\title{
Flow dynamics past a 30P30N three-element high-lift airfoil using Improved Delayed Detached-Eddy Simulation
}

\author{
Neil Ashton* \\ Modelling 83 Simulation Group, University of Manchester, Manchester, UK \\ Alastair West $^{\dagger} \quad$ Fred Mendonça ${ }^{\ddagger}$ \\ CD-adapco, London, W6 $7 N L, U K \quad$ Independant Consultant, London, UK
}

\section{Nomenclature}

c Chord length of stowed configuration

$C_{d} \quad$ Drag coefficient (scaled by planform area $c \cdot b_{\text {sim }}$ )

$C_{L} \quad$ Lift coefficient (scaled by planform area $c \cdot b_{\text {sim }}$ )

$C_{L, s} \quad$ Lift coefficient (scaled by planform area $c \cdot b_{\text {sim }}$ ) from slat

$C_{L, m} \quad$ Lift coefficient (scaled by planform area $c \cdot b_{\text {sim }}$ ) from main wing

$C_{L, f} \quad$ Lift coefficient (scaled by planform area $c \cdot b_{\text {sim }}$ ) from flap

$C_{p} \quad$ Pressure coefficient $=\left(p-p_{\infty}\right) /\left(0.5 \rho_{\infty} U_{\infty}^{2}\right)$

$L_{z} \quad$ Spanwise extent of computational domain

$N_{\text {sub }} \quad$ Number of inner iterations per time step

$N_{t, \text { transient }}$ Simulation time before sampling

$N_{t, \text { sampling }}$ Simulation time during sampling

$T K E_{2 D} \quad 2 \mathrm{D}$ resolved turbulent kinetic energy , $0.5\left(u^{\prime 2}+v^{\prime 2}\right) / U_{\infty}^{2}$

Re $\quad c U_{\infty} / \nu$

$\Omega_{z} \quad$ Non-dimensional spanwise vorticity scaled by $U_{\infty} / c$

$\Delta \quad$ Grid spacing along specified coordinate direction

M-B Multi-Block

C-P Cartesian-Prismatic

\footnotetext{
*Present affiliation: Visiting Research Fellow, Oxford e-Research Centre, University of Oxford, AIAA Member, neil.ashton@oerc.ox.ac.uk

${ }^{\dagger}$ Senior Engineer, CD-adapco, AIAA Member

${ }^{\ddagger}$ Currently Director of Operations, OpenCFD, AIAA Member
} 


\section{Introduction}

Noise emissions from commercial aircraft during take-off and landing is a crucial limiting factor in the expansion of current airports, both in terms of their operating hours and geographical location. A reduction in noise emissions could allow for longer operating periods and a decrease in the number and severity of planning permission delays from local residents and businesses. A major contribution of noise radiation from a commercial airliner is its high-lift system, in particular the leading edge slat. ${ }^{1}$ The unsteady flow separation from the leading edge of the slat produces a separated shear layer which when reattaching further downstream produces a broadband noise source. ${ }^{2}$

Many design studies now use Computational Fluid Dynamics (CFD) as their primary design tool, thus establishing a CFD methodology that can predict this noise accurately is key. The slat cove region exhibits a range of complex flow features, which makes the prediction of this with CFD a challenge, especially with traditional Reynolds-Averaged Navier-Stokes (RANS) approaches. Furthermore, the application of a wall-resolved Large Eddy Simulation (LES) is prohibitively expensive for such a wall-bounded flow at this reasonable Reynolds number (even if the slat shear layer itself could be resolved). ${ }^{3}$ For this reason hybrid RANS-LES methods, which seek to combine the advantages of both RANS and LES methods are an attractive modelling choice.

Recently, several workshops organised by the American Institute of Aeronautics and Astronautics (AIAA) have attempted to address these challenges. ${ }^{2}$ These BANC a workshops have focused on assessing and improving CFD and experimental methods for the accurate prediction of noise sources from an aircraft. For the CFD studies, the impact of grid resolution, turbulence modelling approaches and numerical schemes have been assessed by a range of organisations and academic institutions.

Within the framework of the BANC III workshop, this paper discusses the performance of a particular hybrid RANS-LES approach (Improved Delayed Detached-Eddy Simulation (IDDES)) ${ }^{4}$ on a cartesian-prismatic unstructured grid as well as a multi-block structured grid for the simulation of a three-element airfoil. Structured meshes can often ensure greater accuracy at the cost of significantly longer generation times, especially for new or modified geometries which cannot be generated from previously generated scripts. Whilst unstructured approaches offer much quicker, largely automated grid generation, quality can be difficult to guarantee due to the automated nature of its generation.

Thus the aims of this paper are to:

- Assess the capability of IDDES to accurately predict the flow dynamics from the leading edge slat of a generic three-element airfoil.

- Compare a multi-block structured and cartesian-prismatic unstructured grid using the same turbulence modelling approach, numerical scheme and finite-volume code.

\footnotetext{
${ }^{\mathrm{a}}$ Workshop on Benchmark problems for Airframe Noise Computations
} 


\section{Computational Set-up}

The geometry used in this paper is the modified-slat 30P30N high-lift three-element airfoil (Figure 1). This has been used in several BANC workshops, as well as for other investigations at NASA Langley Research Center (LaRC). The flow properties are summarised in Table 1, where the Reynolds number based on stowed cord, $c$ and free-stream velocity, $U_{\infty}$ is 1.71 Million. This airfoil has been experimentally investigated by several organisations ${ }^{1,5,6}$ providing both mean quantities such as force and pressure coefficients as well as PIV planes for velocity components, Turbulent Kinetic Energy (TKE) and vorticity. Additionally surface pressure spectra around the slat cove region is available at several locations.

\begin{tabular}{|c|c|c|c|c|c|c|}
\hline AoA & $M$ & $c(m)$ & $c_{s}(m)$ & $U_{\infty}\left(\mathrm{m} \mathrm{s}^{-1}\right)$ & $T_{\infty}(\mathrm{K})$ & $R e$ \\
\hline \hline 5.5 & 0.17 & 0.457 & 0.0685 & 58.6 & 295.56 & $1,710,000$ \\
\hline
\end{tabular}

Table 1. Flow properties.

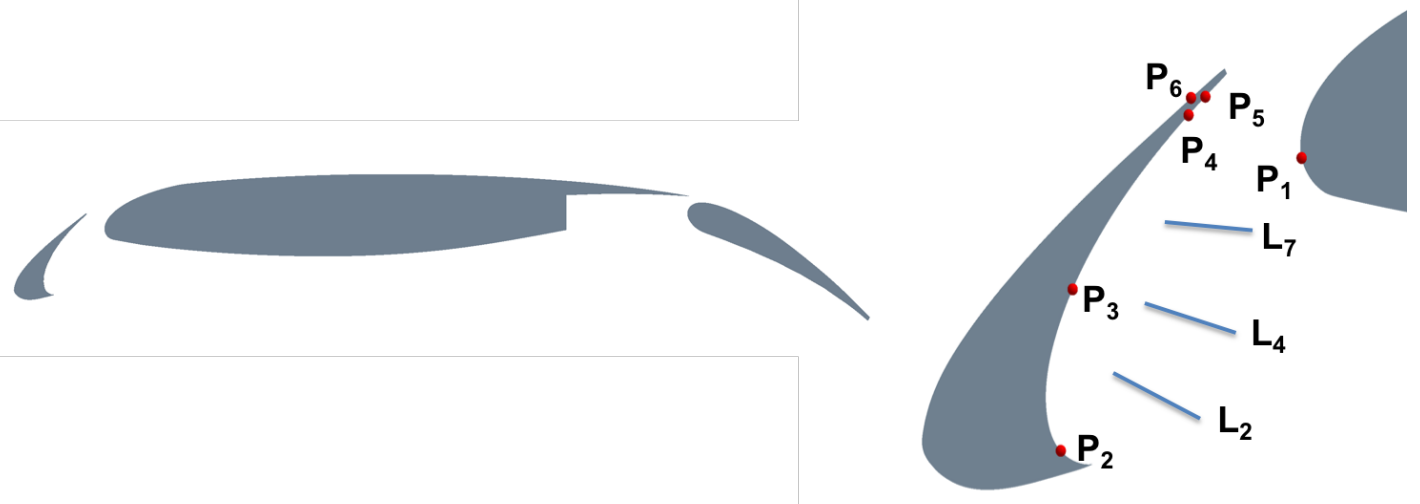

Figure 1. 30P30N three-element airfoil (left) and approximate surface pressure probe positions (right)

\section{A. Computational Grid}

Two meshes were used in this study; a multi-block structured grid (M-B Structured in Figures) provided by JAXA and an cartesian-prismatic unstructured grid (C-P Unstructured in Figures) automatically generated by STAR-CCM+. The aim is to compare manually created structured meshes (which are often later scripted to become automated) against automatically generated unstructured meshes, which form the basis of the majority of commercial CFD codes.

For the structured mesh (shown in Figure 2(a)), 105 point-matched blocks were used in a 2D plane consisting of 271,739 points. This was then extruded in the span wise direction with 271 points over $0.0508 \mathrm{~m}$ (11\% of the chord). The first near-wall cell height was chosen to ensure a $y^{+}<1$. The total cell count of the mesh is approximately 73 million cells. 
The unstructured mesh (see Figure 2(b)) consists of body-fitted prismatic layers cut into a background cartesian mesh. This mesh therefore inherits some of the characteristics of the multi-block structured mesh compared to tetrahedral or polyhedral unstructured meshes. Refinements are made via user-specified zones using hanging nodes. The size of the cells in the slat cove region were created to be approximately the same size as the structured grid to ensure similar resolution, although in the initial shear layer the structured grid has finer resolution. The first near-wall cell height was also chosen to ensure a $y^{+}<1$ and the stretching ratio of adjacent prism layers was 1.1. The span wise extent was also $0.0508 \mathrm{~m}$ and the $\Delta z$ varied according to the refinement boxes (isotropic cells were ensured within the slat region). Several refinement zones were used to reduce the total cell count, thus enabling the total cell count to be 55 million cells.

The mesh was generated using industrial best-practice guidelines and took several days to design and generate. This decision was made to assess the type of mesh a CFD engineer might make within an aerospace company for a production run, and is in contrast to the several weeks required to create a structured mesh from new (although it is noted that further optimization of the unstructured grid could be made). This difference in the time to design and generate the mesh is most noticeable when brand new geometry or one with sufficiently changed features is used such that a previous meshing script cannot be used.

Although structured typically refers to the way the grid information is addressed computationally (i.e a direct mapping between the physical space and the computational storage), in this paper both meshes are treated in the same unstructured finite-volume framework.

\section{B. Numerical Methods}

The commercial CFD code STAR-CCM+ is used for all simulations. This code is a cell-centered finitevolume solver using cells of arbitrary polyhedral shape. A compressible (pressure-based) implicit unsteady segregated solver is used here with a Rhie-Chow interpolation to avoid oscillations. ${ }^{7}$ An implicit $2^{\text {nd }}$ order temporal scheme is used with a non-dimensional time step of $\Delta t \times U / c=1.46 \times 10^{-4}$, with 5 inner iterations per time step for each simulation, which ensured a convective $C F L$ number below one and a drop of three orders of magnitude for the residuals per time-step. No-slip conditions are prescribed at the airfoil walls with periodic conditions at the lateral boundaries. Non-reflecting farfield boundary conditions are used for all remaining outer boundaries. All simulations were initialized using a converged steady RANS solution, after which six flow-throughs $(t \times U / c)$ were completed before time-averaging began for a further 13 and 7 flow-throughs for the structured and unstructured grids respectively.

\section{Turbulence Modelling}

Steady RANS computations were conducted using the Spalart-Allmaras (SA) ${ }^{8}$ and $\mathrm{k}-\omega \mathrm{SST}^{9}$ models. The purpose of these calculations were firstly to establish the suitability of the RANS model choice in a hybrid RANS-LES framework and secondly to provide a comparison between the predictive capability of both mesh types. Additionally each hybrid RANS-LES computation was initialised using a RANS solution to reduce the computational time. All simulations was run fully-turbulent (i.e no transition model). 


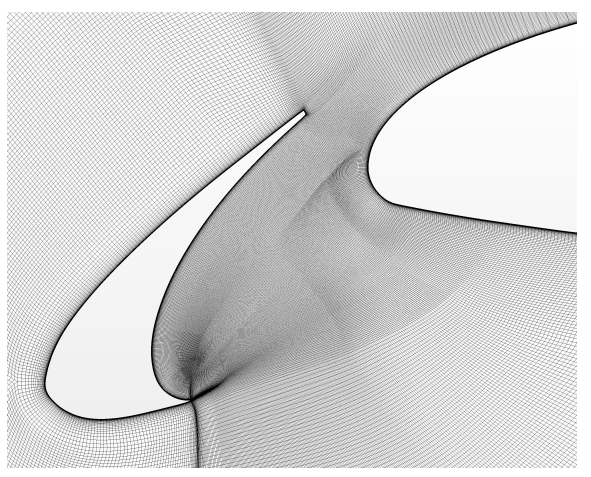

(a)

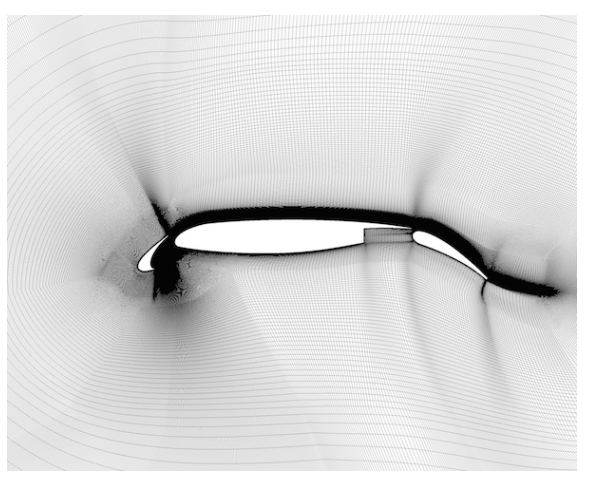

(c)

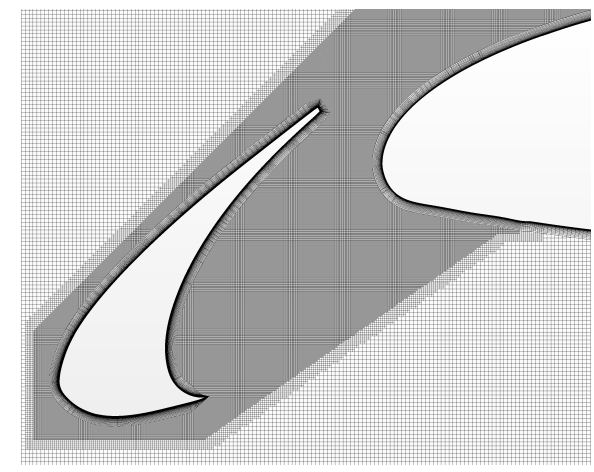

(b)

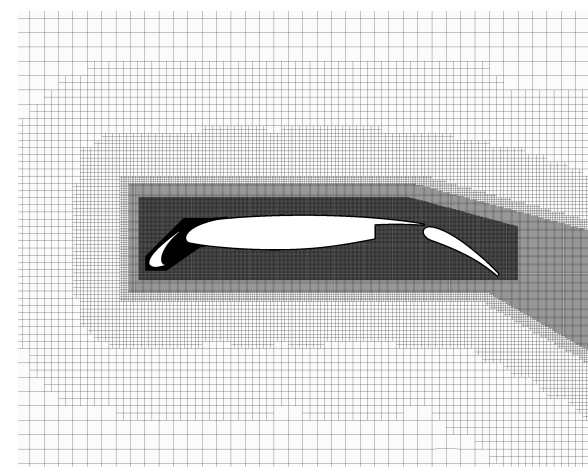

(d)

Figure 2. Close-up view of the slat region of (a) M-B structured grid and (b) C-P unstructured grid and the complete grid for the (c) M-B structured and (d) C-P unstructured grid

The hybrid RANS-LES computations used Detached Eddy-Simulation (DES), ${ }^{3}$ in particular the Improved Delayed Detached Eddy Simulation (IDDES) ${ }^{4}$ variant using the SST model as the underlying RANS model with the most recently published model coefficients. ${ }^{10}$ This was chosen as it represents one of the most common and well validated hybrid RANS-LES model in use in the aerospace industry and has shown improved performance over DDES for a number of separated flows. ${ }^{4}$

The choice between RANS and LES regions in IDDES is dictated by Equation 1, which uses a blending function $\tilde{f}_{d}$ to decide between a RANS or LES turbulent length scale.

$$
L_{I D D E S}=\tilde{f}_{d} L_{R A N S}+\left(1-\tilde{f}_{d}\right) L_{L E S}
$$

Where $L_{L E S}$ and $L_{R A N S}$ represent the LES and RANS length scales respectively.

$$
\begin{aligned}
L_{L E S} & =C_{D E S} \Delta_{I D D E S} \\
L_{R A N S} & =\sqrt{k} / c_{\mu} \omega
\end{aligned}
$$

$C_{D E S}$ is an empirical constant and $\Delta_{I D D E S}$ is the IDDES length scale, defined as:

$$
\begin{aligned}
\Delta_{I D D E S} & =\min \left(\max \left[C_{w} d_{w}, C_{w} h_{\max }, h_{w n}\right], h_{\max }\right) \\
h_{\max } & =\max (\Delta x, \Delta y, \Delta z)
\end{aligned}
$$


$\Delta x, \Delta y, \Delta z$ is the grid spacing in the $x, y$ and $z$ directions, $C_{w}=0.15$ is an empirical constant, $d_{w}$ is the wall-distance and $h_{w n}$ is the grid step in the wall-normal direction. The purpose of this is to reduce the filter width near the wall which in turn lowers the turbulent viscosity and resolves more of the boundary layer.

The $\tilde{f}_{d}$ function shown in Equation 6, contains two additional blending functions which represent a DDES-type of shielding $\left(f_{d t}\right)$ and one suitable for WMLES $\left(f_{B}\right)$.

$$
\tilde{f}_{d}=\max \left[\left(1-f_{d t}\right), f_{B}\right]
$$

$f_{d t}$ is the modified DDES blending function $f_{d t}=1-\tanh \left[\left(20 r_{d t}\right)^{3}\right]$.

$$
r_{d t}=\frac{\nu_{t}}{\sqrt{U_{i, j} U_{i, j}} \kappa^{2} y^{2}}
$$

The blending function $f_{B}$ is of the form:

$$
f_{B}=\min \left[2 \exp \left(-9 \alpha^{2}\right), 1.0\right]
$$

Where $\alpha=0.25-d_{w} / h_{\max }$.

\section{Hybrid Numerical Scheme}

Recent work to validate and calibrate these DES variants in STAR-CCM+ has been completed by the author, including a comparison of different numerical schemes using Decaying Isotropic Turbulence. ${ }^{11}$ Based upon this work, a hybrid $2^{\text {nd }}$ order upwind/central-differencing discretization scheme (UDS/CDS) ${ }^{12}$ is used to ensure that the RANS and LES regions have the appropriate spatial discretisation scheme.

The full formulation and rationale of this blending function is provided in Travin et al., ${ }^{12}$ however Equation 9 below shows its basic form. $F_{i n v}$ are the invisid fluxes of the momentum equations, with $F_{C D S}$ and $F_{U D S}$ being their approximations using a central differencing scheme and an upwind based scheme respectively. $\sigma$ is a blending function that is designed to be 0 in LES regions and 1 in RANS regions. An illustration of this blending function is provided in Figure 3 where the colour scheme represents a blend between fully $2^{\text {nd }}$ order UDS at 1 to purely CDS at 0 . A $2^{\text {nd }}$ order upwind scheme is applied to the turbulent variables. It can be seen that as the blending function is dependant on flow quantities, such as the strain rate, the allocation of schemes is linked to whether the IDDES model is in LES or RANS mode and thus differs between the grids. This is will discussed further in the following sections.

$$
F_{i n v}=(1-\sigma) F_{C D S}+\sigma F_{U D S}
$$

\section{Results}

Figures 4(a) \& 4(b) show the mean pressure coefficient obtained using the SST RANS and SST-IDDES models for both meshes compared to experimental data at $\alpha=5.5^{\circ}$. For both the RANS and IDDES models, there are only small differences between each mesh. Table 2 shows the mean aerodynamic forces where it can 


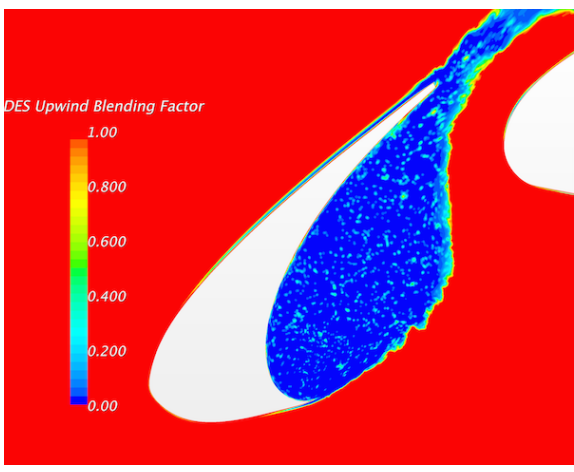

(a)

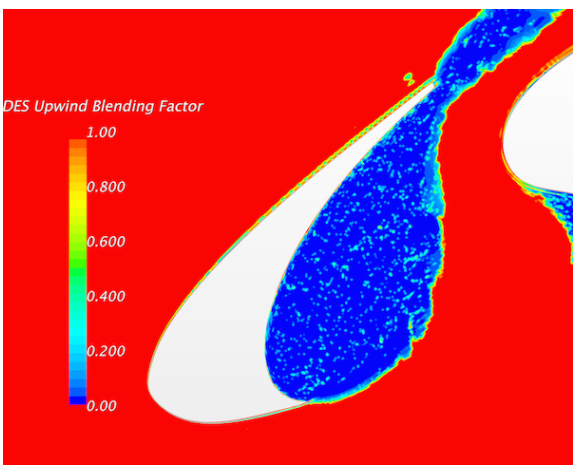

(b)

Figure 3. Hybrid numerical scheme blending function (1: UDS, 0: CDS) for (a) M-B structured and (b) C-P unstructured grids.

be seen that the overall $C_{L}$ is similar between both approaches, however the contribution from each element is different. Due to a coarser mesh over the flap area for the C-P unstructured mesh, the flap lift is lower together with higher $C_{D}$ which is due to slight flow separation from the flap. We note that other groups have addressed this by manually forcing a RANS region here. ${ }^{13}$ The lift and pressure coefficients from both grids agree well with the median of the results predicted by the participants of the BANC III workshop. ${ }^{2}$

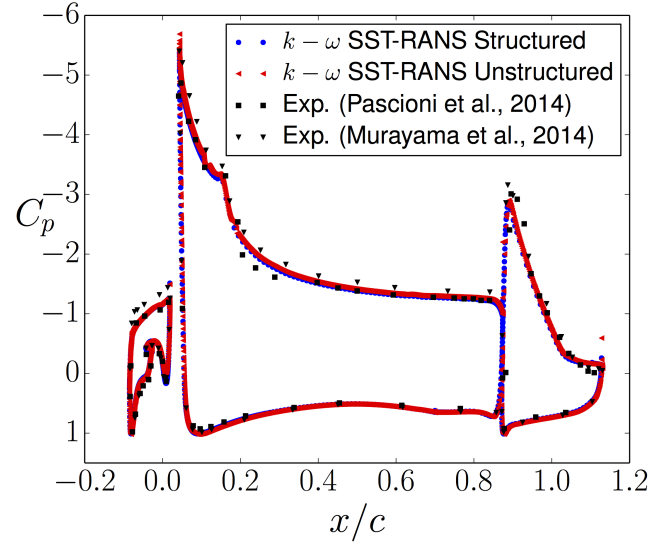

(a)

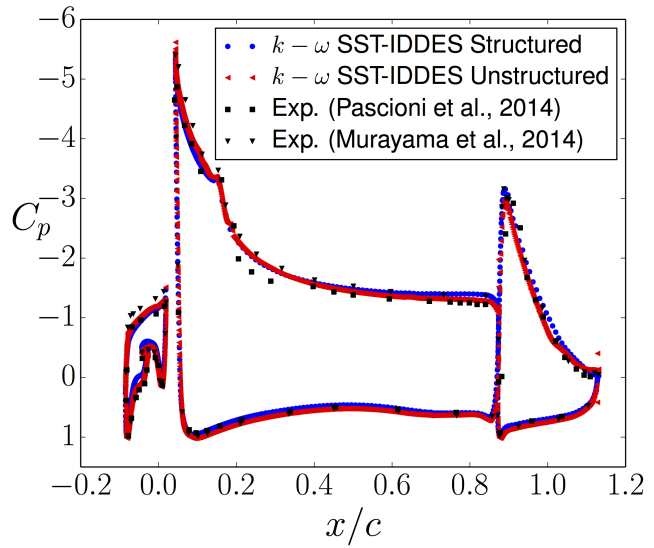

(b)

Figure 4. Mean pressure coefficient obtained from (a) 3D steady SST-RANS and (b) 3D unsteady SST-IDDES compared to experiments at $\alpha=5.5^{\circ}$.

Figure 5(a) shows the mean streamlines from the SPIV measurements of Pascioni et al. ${ }^{5}$ compared to the current IDDES computations on the M-B structured grid (Figure 5(b)) and the C-P unstructured grid (Figure 5(c)). The shear-layer impingement point (distance between slat trailing edge and shear-layer impingement point) is similar between both grid types (see Table 2) and is in very good agreement with both the data from Pascioni et al. ${ }^{5}$ and Jenkins et al. ${ }^{6}$ under similar flow conditions as well as the median results from BANC III participants. ${ }^{2}$ 


\begin{tabular}{|c|c|c|c|c|c|c|}
\hline Model & $C_{L}$ & $C_{D}$ & $C_{L, s}$ & $C_{L, m}$ & $C_{L, f}$ & Impingement distance \\
\hline \hline BANC III Workshop Median $^{2}$ & 2.64 & $\mathrm{n} / \mathrm{a}$ & $\mathrm{n} / \mathrm{a}$ & $\mathrm{n} / \mathrm{a}$ & $\mathrm{n} / \mathrm{a}$ & $16.6 \mathrm{~mm}$ \\
\hline SST IDDES (M-B Structured) & 2.631 & 0.135 & 0.089 & 2.058 & 0.485 & $16.5 \mathrm{~mm}$ \\
\hline SST IDDES (C-P Unstructured) & 2.648 & 0.184 & 0.110 & 2.081 & 0.455 & $17.0 \mathrm{~mm}$ \\
\hline
\end{tabular}

Table 2. Predicted aerodynamics properties.

Figure 6 shows the turbulent viscosity ratio for each mesh. This gives an indication of the level of dissipation arising from the sub-grid scale model (or the RANS model in the case of this hybrid RANS-LES model) as well as whether the model is in RANS or LES mode. The overall levels for both meshes are in the order of $1-5$ which shows that the mesh resolution is suitable for LES content and satisfies one aspect of best-practice guidelines for LES. ${ }^{14}$ For the C-P unstructured mesh (Figure 6(b)) the levels are lower, on both sides of the slat, where the model has moved into an unwanted WMLES mode, which would explain why the turbulent viscosity ratio is lower.

For cases with no inflow turbulence (as in this case) the boundary layers in non-separated regions should be in DDES mode (i.e $\left.\left(1-f_{d t}\right)>f_{B}\right)$ and then in WMLES mode in separated regions (i.e $\left.f_{B}>\left(1-f_{d t}\right)\right)$.

It can be seen in Figure 7 that whilst the M-B structured grid demonstrates the aforementioned characteristics, the C-P unstructured grid does not. This figure shows a 2D profile of various quantities in the boundary layer on the lower side of the slat, but this general trend is seen across the majority of the slat, as shown in Figure 8. The C-P unstructured grid has approximately the same $\Delta y \& \Delta z$ as the M-B structured grid, however $\Delta x$ is smaller which causes $h_{\max }$ to be lower (as the largest grid spacing is in the streamwise direction), which can be seen in Figure 7(d).

The IDDES filter width (Figure $7(\mathrm{e})$ ) contains several variables but it can be seen that it is $C_{w} h_{\max }$ which is used in the majority of the boundary layer, as this is the largest component of the max function in Equation 5 (shown in Figures $7(\mathrm{~g}) \& 7(\mathrm{~h})$ ). Thus the result of this (and the feedback mechanism between $\left.\nu_{t}, r_{d t} \& f_{d t}\right)$ is that the additional refinement in the streamwise direction of the C-P unstructured grid has moved the model into a WMLES-type mode where it should not, as there is no inflow turbulence to develop resolved turbulence. This occurred due to the automated nature of the grid refinement, where specific control on the streamwise spacing in this region was not possible. A 'modelled-stress-depletion'15 situation has therefore arisen where the modelled stress has dropped but there is no resolved turbulence to take its place. This means that the boundary layer is not correctly predicted which impacts upon the development of the initial shear layer. In addition, the grid refinement in the initial separated shear layer is coarser with the C-P unstructured grid thus resulting in a delayed break up into unsteady turbulent structures.

Ultimately this is an artefact of the grid design and the blending function formulation of IDDES, which upon further optimization could be better controlled. It is a note to other users of IDDES to ensure $\Delta_{I D D E S} / \delta$ does not drop too low. The problem of the DDES shielding function has also been noted by Probst et al. ${ }^{16}$ as well as Menter et al. ${ }^{17}$ where it was observed that for $\Delta_{\max } / \delta<0.3$ the DDES shielding 
function broke down, allowing modelled-stress depletion to occur.

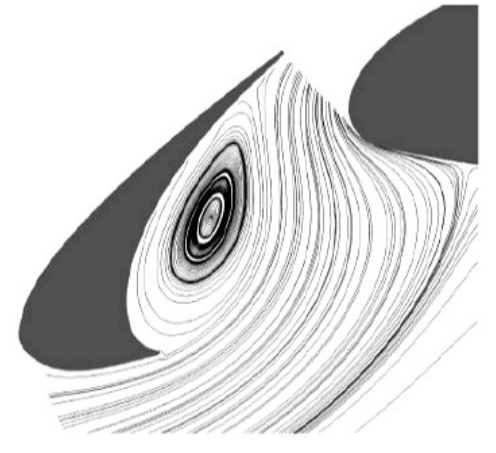

(a)

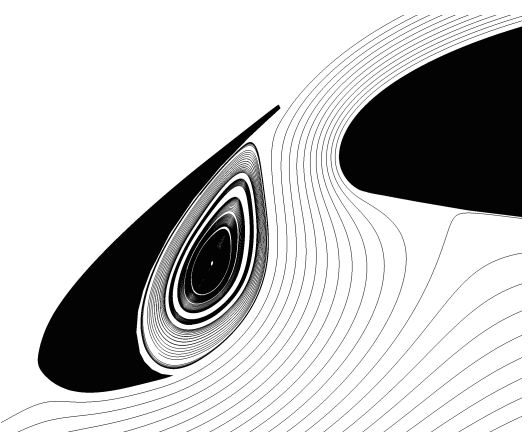

(b)

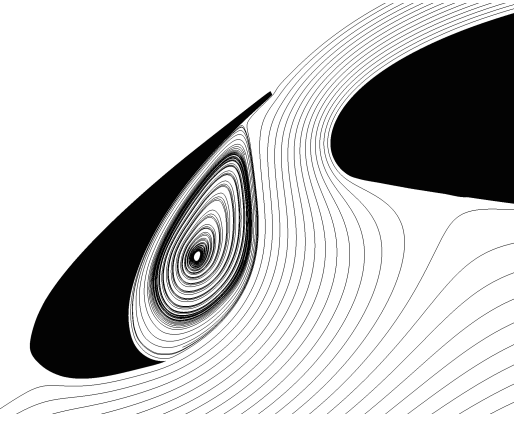

(c)

Figure 5. Mean streamlines from (a) SPIV experiment, (b) M-B structured SST-IDDES and (c) C-P unstructured SST-IDDES.

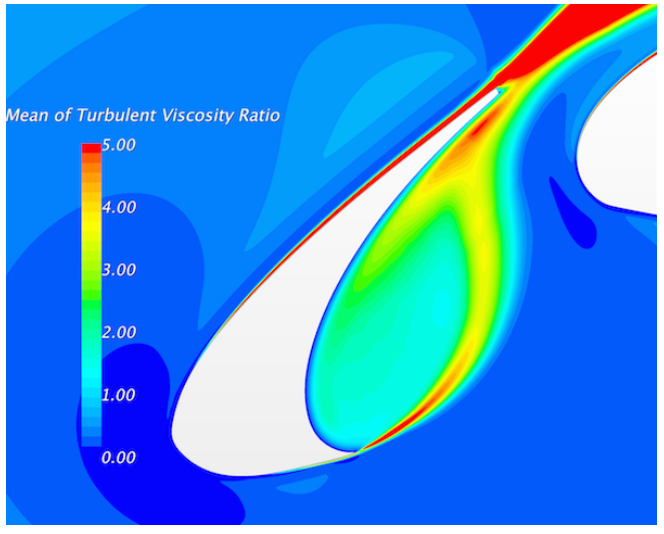

(a)

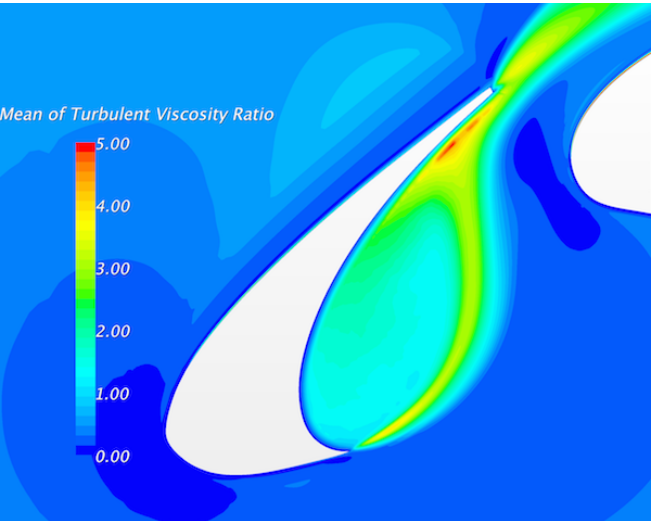

(b)

Figure 6. Mean Turbulent Viscosity Ratio from (a) M-B structured SST IDDES and (b) C-P unstructured SST-IDDES.

The mean resolved 2D turbulent kinetic energy is shown in Figure 9 for both grid types as well from the work of Pascioni et al. ${ }^{5}$. Both grid types show a very similar range of TKE in the impingement region, with the main differences occurring towards the beginning of the shear layer. Here the M-B structured mesh shows initially higher values as the shear layer forms from the slat leading edge, with the C-P unstructured mesh starting smaller but then reaching a slightly higher value further downstream. The distribution and magnitude of TKE agrees well with the majority of BANC III participants ${ }^{2}$ as well as the recent work of Terracol et al., ${ }^{18}$ who used the same M-B structured grid as this study.

This hypothesis of modelled-stress-depletion is largely proven correct by the modeled TKE levels in Figure 10. Here we see that in the initial separated shear layer and also in the boundary layer leading up to the slat leading edge, the C-P unstructured mesh has considerably lower levels than the M-B structured mesh ( $\times 4$ less). Whilst the modeled turbulence only contributes approximately $10 \%$ of the total TKE, in this 


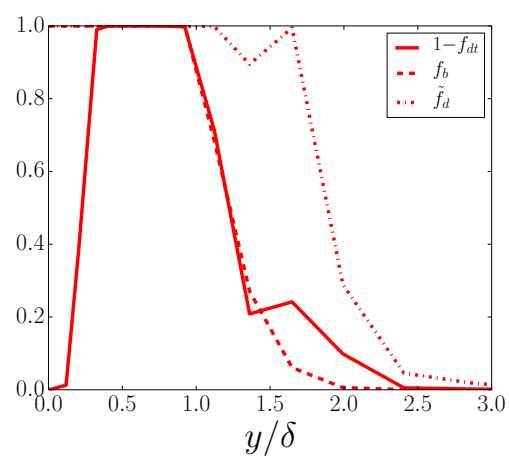

(a)

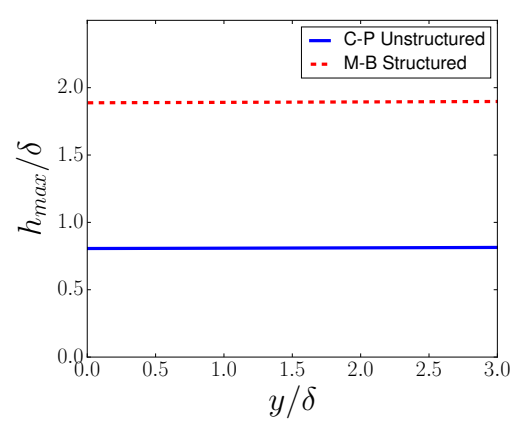

(d)

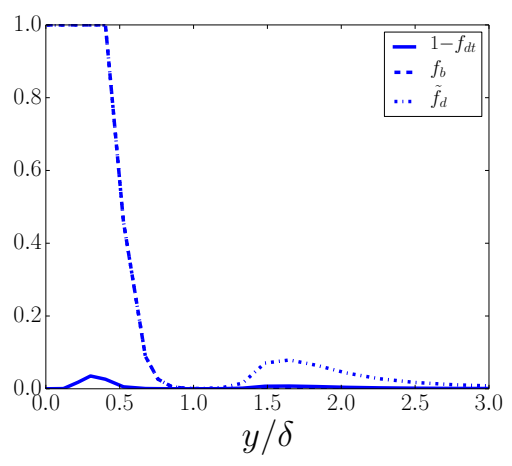

(b)

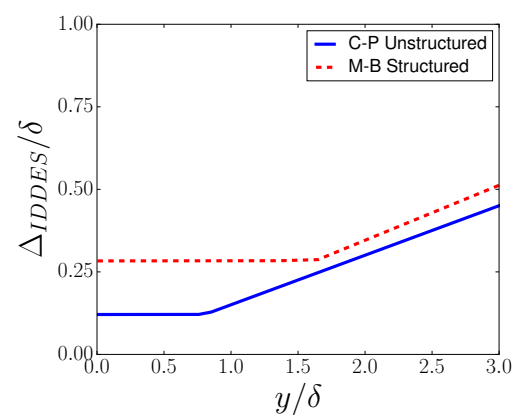

(e)

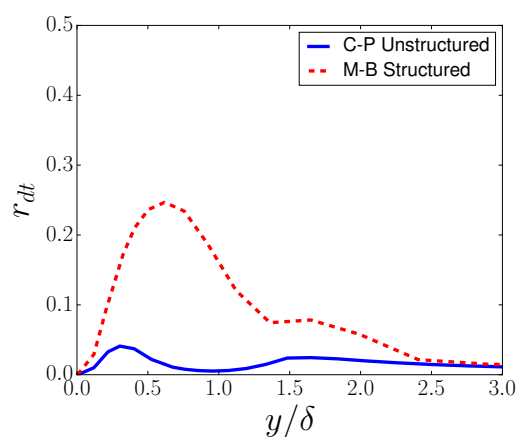

(c)

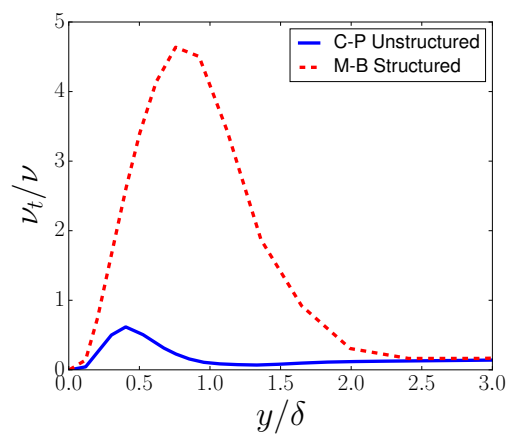

(f)

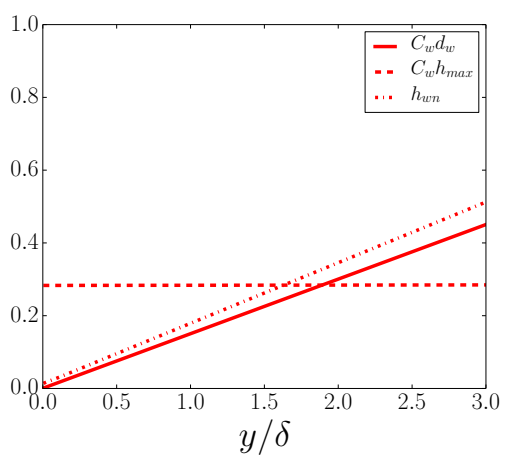

(g)

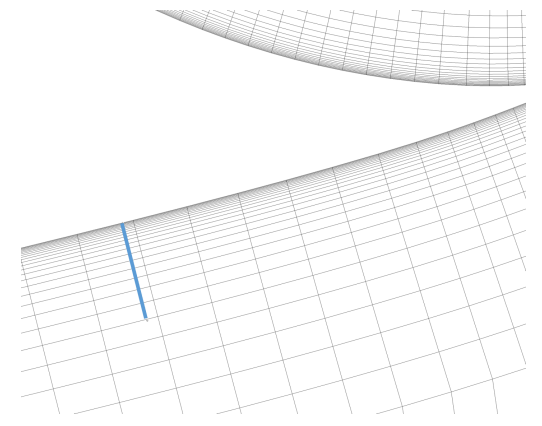

(i)

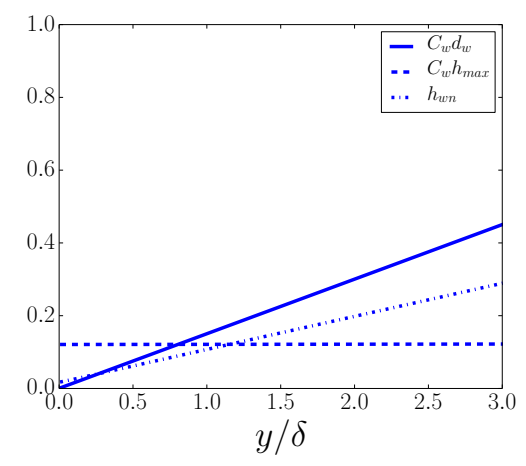

(h)

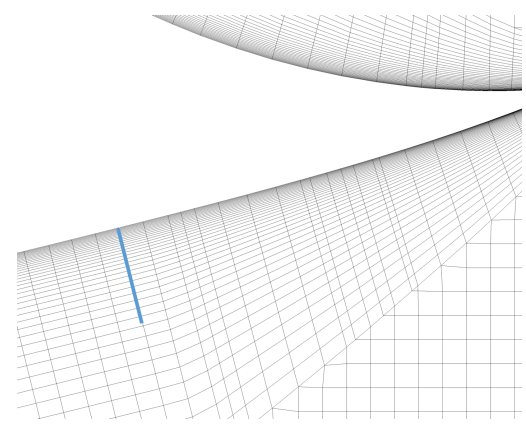

(j)

Figure 7. $\tilde{f}_{d}, f_{d t}, f_{B}$ for (a) M-B Structured and (b) C-P Unstructured meshes. (c) $r_{d t}$, (d) $h_{\max } / \delta,(\mathrm{e}) \Delta_{I D D E S} / \delta$ (f) Turbulent Viscosity Ratio, (g) contributors to $\Delta_{I D D E S}$ for M-B structured mesh, (h) contributors to $\Delta_{I D D E S}$ for C-P unstructured mesh, (i) M-B Structured grid in region of chosen profile, (j) C-P Unstructured grid in region of chosen profile. 


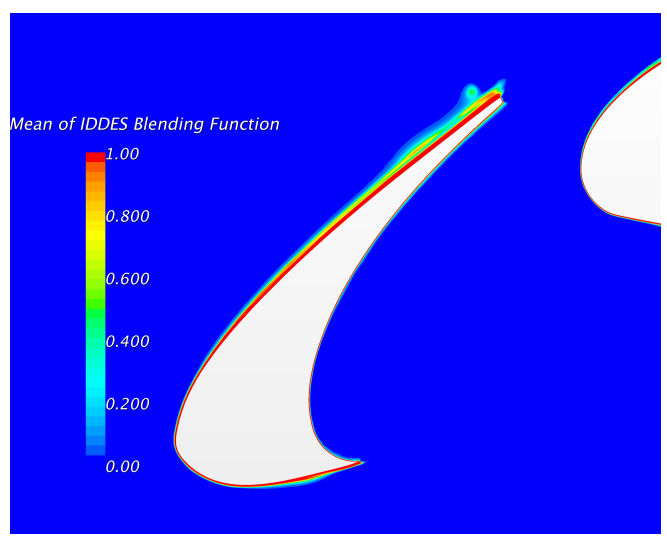

(a)

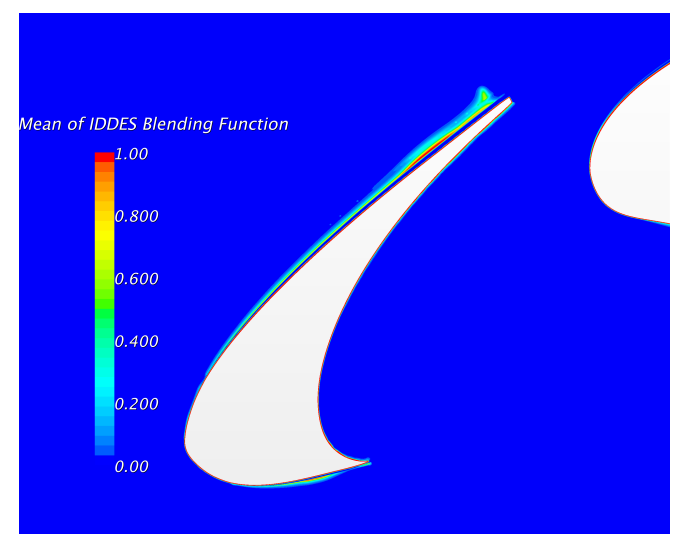

(b)

Figure 8. Mean of IDDES blending function $\left(\tilde{f}_{d}\right)$ from (a) M-B structured SST IDDES and (b) C-P unstructured SST-IDDES.

region it is the modeled turbulence which accounts for almost all of the turbulence. Thus the fact that the C-P unstructured mesh shows very little modelled (and resolved) TKE, means that there is little turbulent mixing to break up the shear layer. This is clearly observed in the instantaneous spanwise vorticity in Figure 13, where the C-P unstructured grid has a thicker shear layer.

An additional problem (for both grids) is the grey-area problem which has been observed for many flows ${ }^{19}$ and is due to a slow transition between modelled and resolved turbulence in the initial separated shear layer. It is a function of the hybrid RANS-LES formulation but also the mesh resolution and numerical scheme, as discussed in Ashton et al. ${ }^{20}$ As the C-P unstructured grid has coarser grid resolution in this area, it is suffering from both the grey-area problem and modelled-stress depletion. For both grids, the appearance of the grey-area is a turbulence modelling issue and thus improved hybrid RANS-LES methods, such as those currently being developed during the Go4Hybrid project, ${ }^{19}$ (for example the new approach of Mockett et al. ${ }^{21}$ or ZDES of Deck et al. ${ }^{22}$ ) amongst other work may help.

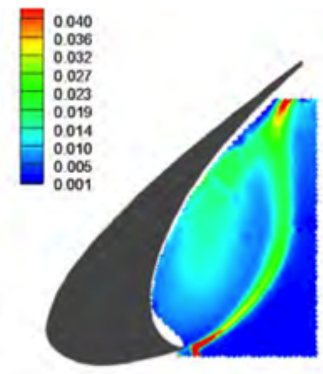

(a)
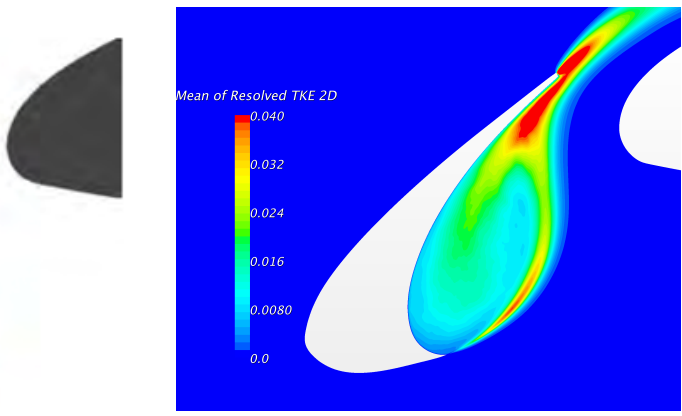

(b)

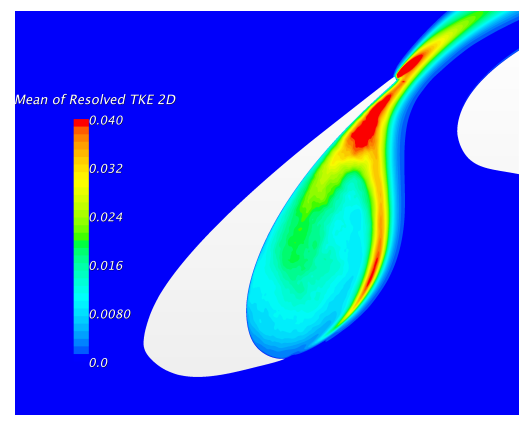

(c)

Figure 9. Mean resolved 2D Turbulent Kinetic Energy (TKE) from (a) experiment SPIV (total TKE) (b) M-B structured SST IDDES and (c) C-P unstructured SST-IDDES. 


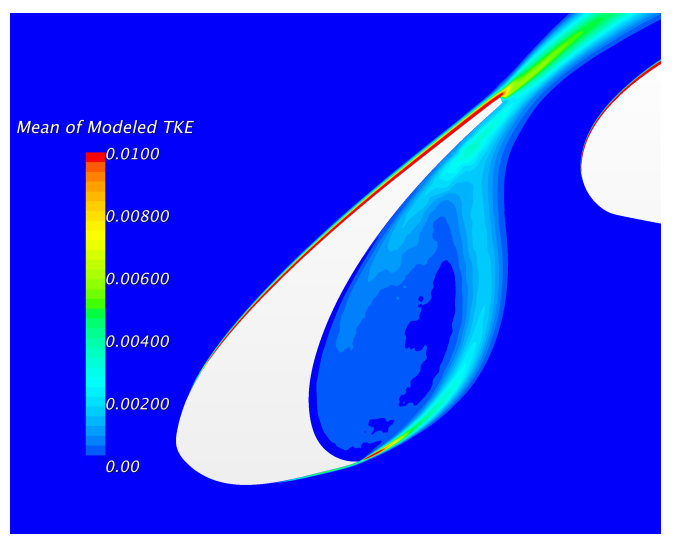

(a)

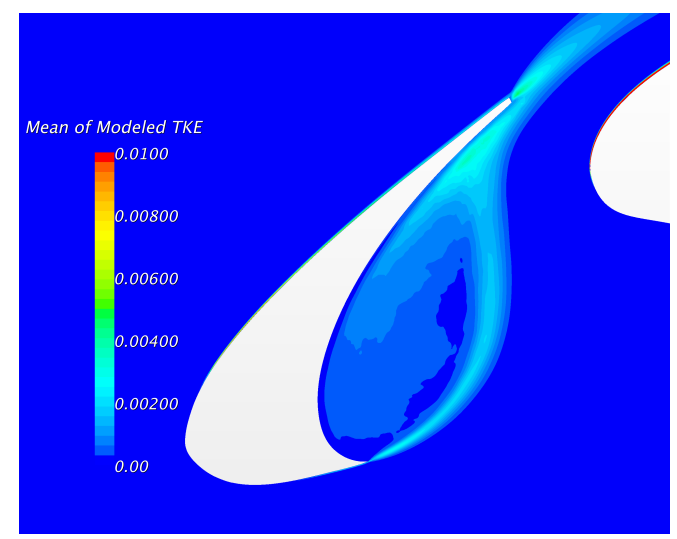

(b)

Figure 10. Mean Modeled 2D Turbulent Kinetic Energy (TKE) from (a) M-B structured SST IDDES and (b) C-P unstructured SST-IDDES.

This variation in the TKE and also the position and velocity of the shear layer is seen more clearly in the line profiles through the shear layer, as shown in Figure 11 (line locations shown in Figure 1). The position and velocity of the shear layer through positions L2, L4 \& L7 is very similar between both the grid types. Compared to the experimental data of Pascioni et al. ${ }^{5}$ the shear layer position in the initial region is shifted in the upstream direction, although the agreement by L4 and L7 is much closer to the experiment. The velocity profiles match the experiment well, thus the difference observed at L2 could be related to CFD error, transition effects or experimental error in the wind tunnel. There is also a noticeable variation between the experiments conducted by Pascioni et al. ${ }^{5}$ and Murayama et al. $^{1}$ in the pressure coefficient for the slat, as shown in Figure 4(a).

As the dominant effect is the impingement of the shear layer on the upper slat region, the close agreement at L7 explains why the actual impingement distance agrees well with the experiment (Figure 5(a)). It is also clear from Figure 12 of the mean spanwise vorticity $\left(\omega_{z} c / U_{\infty}\right)$ that there is generally very good agreement between both CFD simulations and the experimental data. The thickness of the shear layer is one noticeable difference, however the resolution of the PIV is not good enough close to the leading edge to see how the initial shear layer develops compared to the CFD.

The mean and instantaneous spanwise vorticity, as shown in Figures 12 \& 13 highlights the generally good agreement with the experimental data and the similarities between both grid types. The results from the M-B structured grid agree well with the work of Terrocol et al. ${ }^{18}$ who used the same M-B structured grid and DDES model. Whilst Figure 13 is an instantaneous snapshot and therefore at likely different physical states, the turbulent structures are similar. This is also clearly observed in the iso-surfaces of the Q criterion in Figure 14, here for the M-B structured grid, the transition from 2D to 3D structures is visible in the initial shear layer and the fine structures suggest good mesh resolution and low numerical dissipation. The most notable difference between both grids is in the initial shear layer, where as commented earlier, it is 


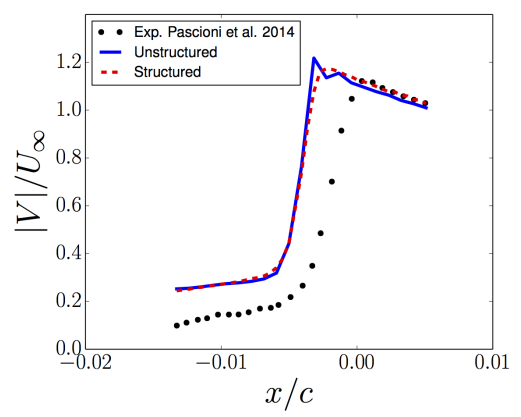

(a)

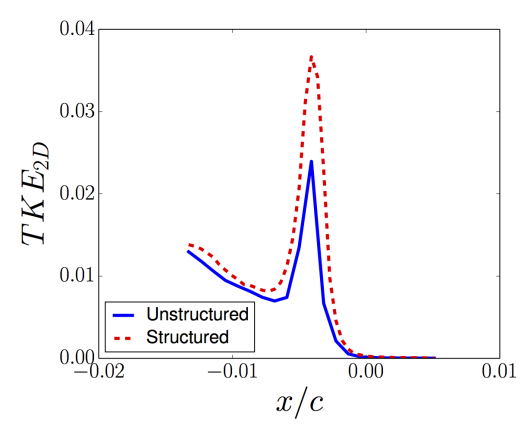

(d)

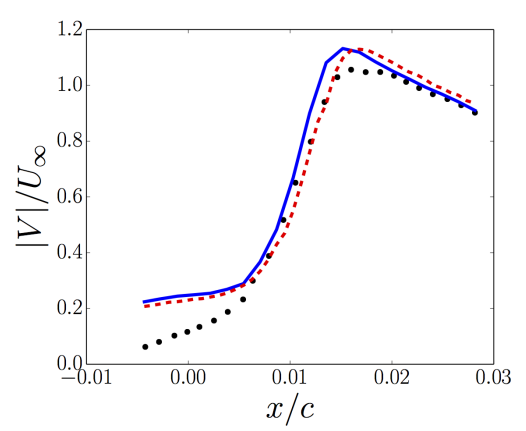

(b)

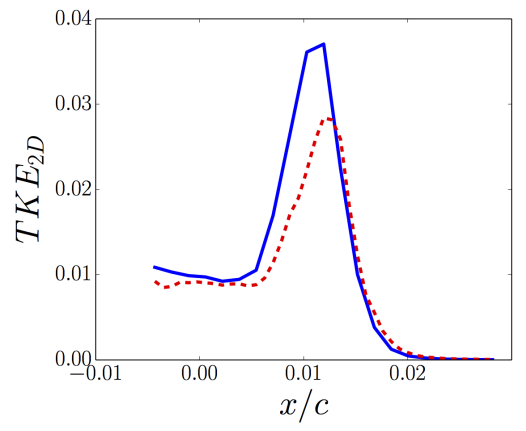

(e)

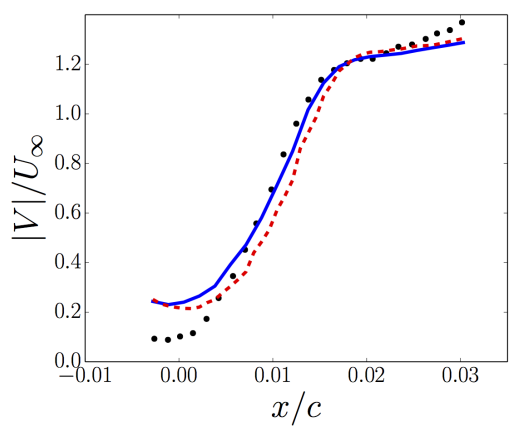

(c)

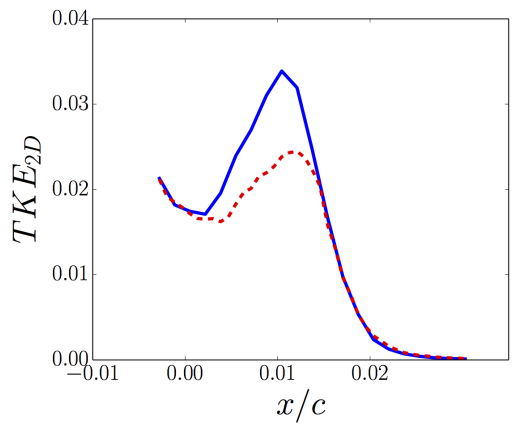

(f)

Figure 11. Mean streamwise velocity at (a) L2, (b) L4 and (c) L7, and Mean Resolved Turbulent Kinetic Energy (TKE) at (d) L2, (e) L4 and (f) L7. 
clear that the shear layer has fewer turbulent structures in the C-P unstructured grid compared to the M-B structured grid. The lack of turbulence and grid resolution in this region means less turbulent mixing and therefore a different shear layer profile. Interestingly between the BANC III participants (shown in Figure 3 in Choudhari et al. ${ }^{2}$ ) there is a split between those who exhibit a thicker more stable initial separated shear layer (as shown in this studies C-P unstructured grid) and those who show a shear layer which breaks down quicker (as the M-B structured grid in this study). There is not a clear reason for this split, as no common grid resolution or turbulence model can explain this alone. It is likely a combination of the insufficient grid resolution, an overly dissipative numerical scheme and possibly a modelled-stress-depletion/grey-area issue as described in this paper.

It can be seen in both Figures $13 \& 14$ that there is evidence of unwanted numerical noise (i.e checker boarding) with the C-P unstructured grid. This is most clearly observed around the initial shear layer region and on the underside of the main airfoil. The authors believe this is due to the hybrid numerical scheme activating CDS in these regions, which is not the case with the M-B structured grid (see Figure 3). Moving to CDS alone isn't necessarily the problem, but combined with the very low turbulent viscosity levels, means that there too little numerical \& turbulent dissipation. This is a downside of an automatic hybrid numerical scheme, based upon flow parameters and the grid itself. A zonal manual allocation of numerical schemes or a redesign of the grid could fix this problem.

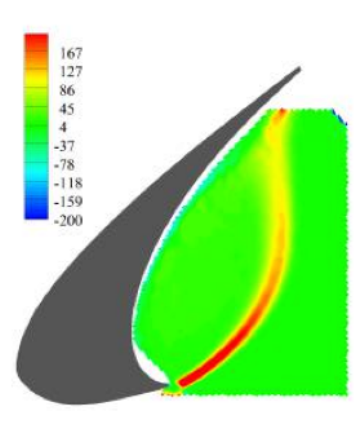

(a)

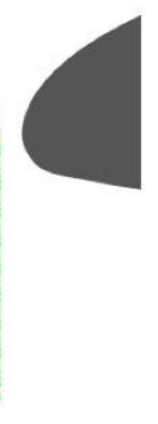

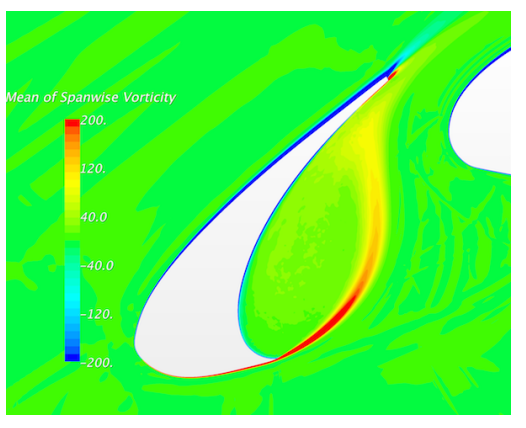

(b)

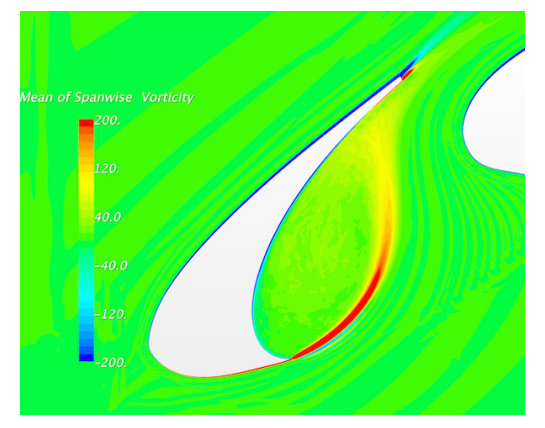

(c)

Figure 12. Mean Spanwise Vorticity from (a) experiment SPIV(b) M-B structured SST IDDES and (c) C-P unstructured SST-IDDES.

Unsteady pressure signals are computed at six chord wise locations as shown in Figure 1. Two of these positions ( $\mathrm{P} 4 \& \mathrm{P} 6)$ are shown in Figure 15. P6 is not directly exposed to the shear layer, whereas $\mathrm{P} 4$ is close to the reattachment location of the slat cove shear layer thus is more sensitive to the impingement location of the shear layer on the slat. Information on the FFT procedure, such as number of samples and frequency of sampling is shown in Table 3. For point P4 it can be seen that the overall broadband levels for both grid types are in good agreement with the measured frequency spectra of Pascioni et al. ${ }^{5}$ and Murayama et al. ${ }^{1}$ There is a noticeable difference between both experiments so it's not possible to conclude with certainty the accuracy of the CFD simulations. Further samples may also yield closer agreement in the low frequency range between both CFD simulations. For P6, again the broadband levels agree well and the experimental 


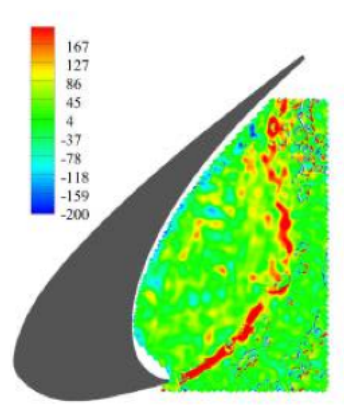

(a)
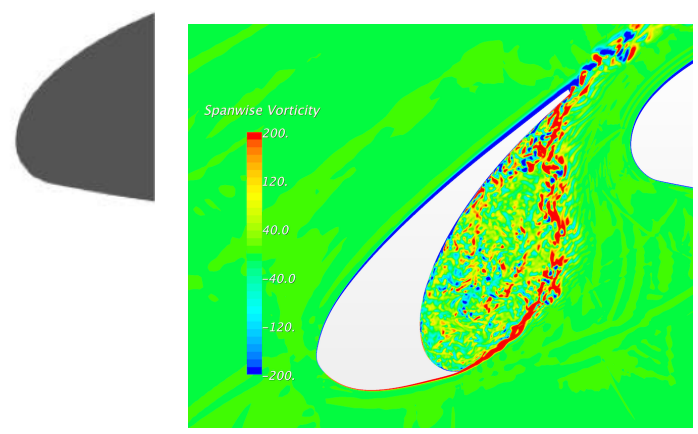

(b)

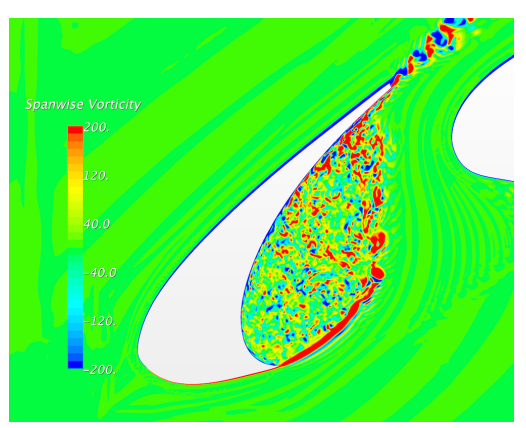

(c)

Figure 13. Instantaneous Spanwise Vorticity from (a) experiment SPIV (b) M-B structured SST IDDES and (c) C-P unstructured SST-IDDES.

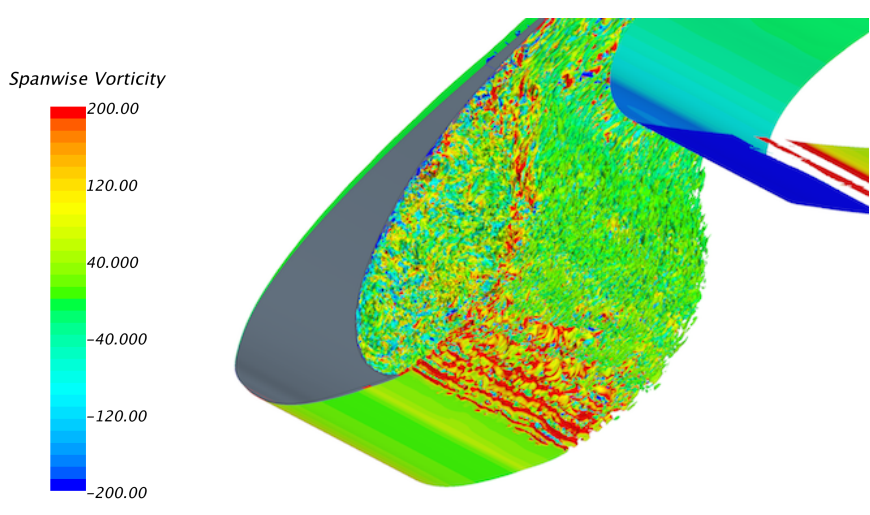

(a)

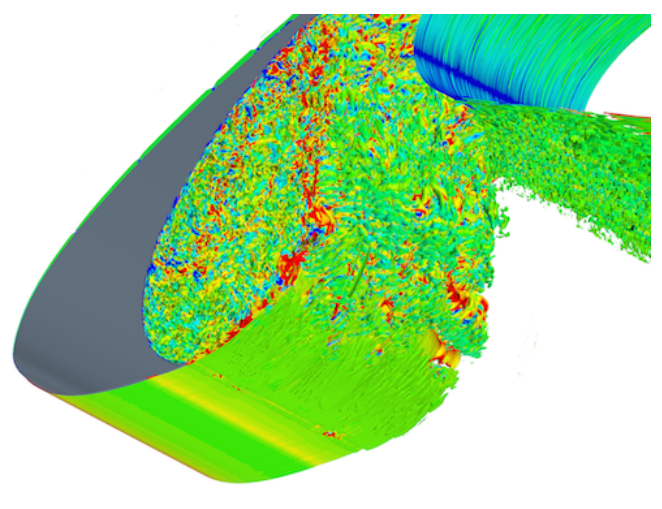

(b)

Figure 14. Instantaneous iso-surfaces of the $\mathbf{Q}$ criterion $\left(Q c / U^{2}=0.07\right)$ coloured by vorticity for the (a) $\mathbf{M}-\mathbf{B}$ structured SST-IDDES and (b) C-P unstructured SST-IDDES models. 
narrow-band peaks are clearly predicted at the locations away from the shear layer impingement (where the high amplitude vortical structures are responsible for the largest overall levels of pressure fluctuations). The lack of samples for the C-P unstructured grid may be masking better agreement but the narrow-band peaks are still well predicted by the C-P unstructured grid. These narrowband peaks are associated with resonant oscillations from a feedback loop whereby the impinging shear layer causes acoustic waves to propagate back to the cusp and excite new structures within the shear layer. Initial results from far-field data suggests that a difference between the two grids is present, but further analysis and data samples are required to make proper conclusions on the far-field noise.

\begin{tabular}{|c|c|c|c|c|c|c|}
\hline Model & $\Delta t \times U / c$ & $N_{\text {sub }}$ & $N_{\text {t,transient }}$ & $N_{t, \text { sampling }}$ & Flow-through times & Bin width $($ Hz) \\
\hline \hline M-B Structured & $1.46 \times 10^{-4}$ & 5 & 0.33 & 0.23 & 13 & 26 \\
\hline C-P Unstructured & $1.46 \times 10^{-4}$ & 5 & 0.23 & 0.12 & 7 & 34 \\
\hline
\end{tabular}

Table 3. FFT analysis parameters.

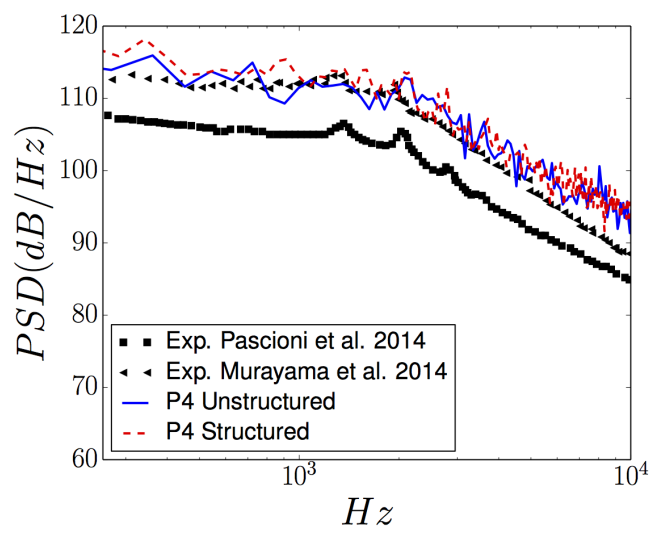

(a)

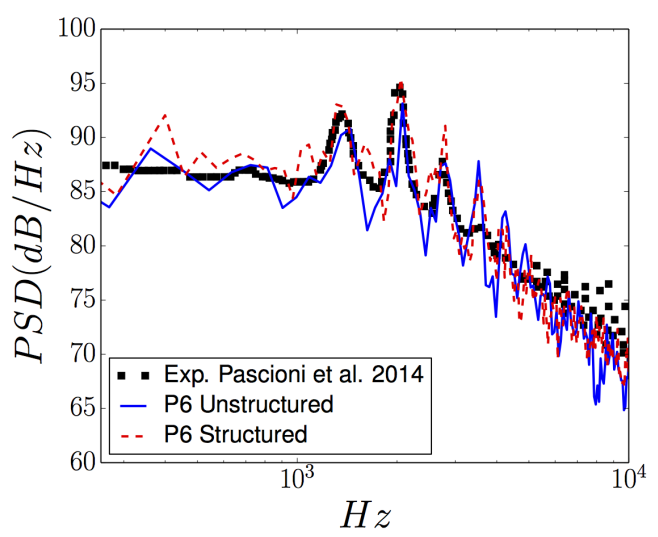

(b)

Figure 15. Power Spectral Density (DB/Hz) from M-B structured and C-P unstructured CFD against experimental data at probes (a) P4 \& (b) P6

\section{Conclusions}

A set of simulations have been conducted on the $30 \mathrm{P} 30 \mathrm{~N}$ high-lift three-element airfoil using a hybrid RANS-LES method on multi-block structured and cartesian-prismatic unstructured grids. These simulations using the SST-IDDES model have been shown to agree well with previous experimental and numerical investigations in terms of mean quantities as well as spectra and flow structures. It has also been shown that results from a cartesian-prismatic unstructured mesh generated in only a few days was able to predict both mean and instantaneous flow features to an acceptable level. However, there were clearly areas where improvements to the mesh, numerical scheme and turbulence model could improve both the correlation to 
the experimental data and to the multi-block structured mesh. It was demonstrated from the grids used in this study that IDDES exhibits a sensitivity to the near-wall meshing, in particular when $\triangle_{I D D E S} / \delta$ drops to low values. At these low values, the shielding function breaks down, and causes the model to move into a WMLES mode even without inflow turbulence, due to an over-refinement of the boundary-layer mesh in the streamwise direction. This particular failure of the IDDES shielding function should be investigated further to both provide best-practice guidelines and to develop a more robust shielding function. Further work to investigate the far-field noise is required however to understand whether any differences between the grids are amplified when assessing the associated acoustics.

\section{Acknowledgements}

The authors gratefully acknowledge computational support from EPSRC for UK's National HPC Facility, ARCHER and Barcelona Supercomputing Centre (BSC) for time on Mare Nostrum through both RES and PRACE. This work also made use of the facilities of N8 HPC provided and funded by the N8 consortium and EPSRC (Grant No.EP/K000225/1). The Centre is co-ordinated by the Universities of Leeds and Manchester. The authors would also like to acknowledge the use of the University of Oxford Advanced Research Computing (ARC) facility in carrying out this work. http://dx.doi.org/10.5281/zenodo.22558 . The authors also would like to thank Mitsuhiro Murayama, Kazuomi Yamamoto and colleagues at JAXA for providing the multi-block structured mesh. Finally the authors would like to thank Meelan Choudhari from NASA Langley Research Centre (LaRC) for his help.

\section{References}

${ }^{1}$ Murayama, M., Nakakita, K., Yamamoto, K., Ura, H., and Ito, Y., "Experimental Study of Slat Noise from 30P30N Three-Element High-Lift Airfoil in JAXA Hard-Wall Low-Speed Wind Tunnel," AIAA 2014 AIAA Aviation and Aeronautics Forum and Exposition, 2014, pp. 6-13.

${ }^{2}$ Choudhari, M. and Lockard, D., "Assessment of Slat Noise Predictions for 30P30N High-Lift Configuration from BANCIII Workshop," AIAA Aviation 2015, 2015.

${ }^{3}$ Spalart, P. R., Jou, W. H., Strelets, M., and Allmaras, S. R., "Comments on the feasibility of LES for wings and on a hybrid, RANS/L ES approach," Advances in DNS/LES, Proceedings of 1st AFOSR International Conference on DNS/LES, Vol. 1, 1997, pp. 137-147.

${ }^{4}$ Shur, M. L., Spalart, P. R., Strelets, M. K., and Travin, A. K., "A hybrid RANS-LES approach with delayed-DES and wall-modelled LES capabilities," International Journal of Heat and Fluid Flow, Vol. 29, No. 6, dec 2008, pp. $1638-1649$.

${ }^{5}$ Pascioni, K. A., Cattafesta, L. N., and Choudhari, M. M., "An Experimental Investigation of the 30P30N Multi-Element High-Lift Airfoil," AIAA 20th AIAA/CEAS Aeroacoustic Conference, 2014, pp. 16-20.

${ }^{6}$ Jenkins, L. N., Khorrami, M. R., and Choudhari, M., "Characterization of Unsteady Flow Structures near Leading-Edge Slat: Part I ." AIAA 10th AIAA/CEAS Aeroacoustics Conference, 2004, pp. 1-15.

${ }^{7}$ Demirdzic, I. and Muzaferija, S., "Numerical method for coupled fluid flow, heat transfer and stress analysis using unstructured moving meshes with cells of arbitrary topology," Computer Methods in Applied Mechanics and Engineering, Vol. 125, No. 1, 1995, pp. 235-255.

${ }^{8}$ Spalart, P. R. and Allmaras, S. R., "A one-equation turbulence model for aerodynamic flows," La Recherche Aerospatiale, Vol. 1, 1994, pp. 5-21. 
${ }^{9}$ Menter, F. R., "Two-Equation Eddy-Viscosity Turbulence Models for Engineering Applications," AIAA, Vol. 32, No. 8, 1994, pp. 1598-1605.

${ }^{10}$ Gritskevich, M. S., Garbaruk, A. V., and Menter, F. R., "Fine-tuning of DDES and IDDES formulations to the k-w Shear Stress Transport model," 4th European Conference for Aerospace Sciences EUCASS4, 2011, pp. 1-10.

${ }^{11}$ Ashton, N., Lardeau, S., Dawson, P., and Revell, A., "Calibration, Validation and Development of DDES Models in a Commerical CFD Solver For Flow Subject To 3D Separation," ETMM10: 10th International ERCOFTAC Symposium on Engineering, 2014.

${ }^{12}$ Travin, A., Shur, M., Strelets, M., and Spalart, P. R., "Physical and numerical upgrades in the detached-eddy simulation of complex turbulent flows," Proceedings of the 412th Euromech Colloquium on LES and Complex Transitional and Turbulent Flows, Munich, 2000.

${ }^{13}$ Lockard, D., Choudhari, M., and Buning, P., "Grid Sensitivity Study for Slat Noise Simulations," 20th AIAA/CEAS Aeroacoustics Conference, , No. June, 2014, pp. 1-13.

${ }^{14}$ Fröhlich, J., Mellen, C. P., Rodi, W., Temmerman, L., and Leschziner, M., "Highly resolved large-eddy simulation of separated flow in a channel with streamwise periodic constrictions," Journal of Fluid Mechanics, Vol. 526, mar 2005, pp. 19-66.

${ }^{15}$ Spalart, P. R., Deck, S., Shur, M. L., Squires, K. D., Strelets, M. K., and Travin, A., "A New Version of Detached-eddy Simulation, Resistant to Ambiguous Grid Densities," Theor. Comput. Fluid Dynam., Vol. 20, No. 3, 2006, pp. 181-195.

${ }^{16}$ Probst, A., Radespiel, R., Wolf, C., Knopp, T., and Schwamborn, D., "A Comparison of Detached-Eddy Simulation and Reynolds-Stress Modelling Applied to the Flow over a Backward-Facing Step and an Airfoil at Stall," New Horizons, , No. January, 2010, pp. 2010-2010.

${ }^{17}$ Menter, F. R., "Stress-Blended Eddy Simulation ( SBES ) A New Paradigm for Hybrid RANS-LES Modelling," Presentation at 2015 Go4hybrid Workshop, Berlin, 2015, pp. 1-68.

${ }^{18}$ Terracol, M., Mahnoha, E., Murayama, M., Yamamoto, K., Amemiya, K., and Tanaka, K., "Aeroacoustic Calculations of the 30P30N High - lift Airfoil using Hybrid RANS / LES methods : Modeling and Grid Resolution Effects," AIAA 21th AIAA/CEAS Aeroacoustics Conference, No. June, 2015, pp. 2-19.

${ }^{19}$ Mockett, C., Haase, W., and Thiele, F., "Go4Hybrid: A European Initiative for Improved Hybrid RANS-LES Modelling," Progress in Hybrid RANS-LES Modelling, Notes on Num. Fluid Mech., 2014, pp. 299-303.

${ }^{20}$ Ashton, N. and Revell, A., "Key factors in the use of DDES for the flow around a simplified car," International Journal of Heat and Fluid Flow, Vol. 54, 2015, pp. 236-249.

${ }^{21}$ Mockett, C., Fuchs, M., Garbaruk, A., Shur, M., Spalart, P., Strelets, M., Thiele, F., and Travin, A., "Two Non-zonal Approaches to Accelerate RANS to LES Transition of Free Shear Layers in DES," Progress in Hybrid RANS-LES Modelling, 2015, pp. 187-201.

${ }^{22}$ Deck, S. and Laraufie, R., "Numerical investigation of the flow dynamics past a three-element aerofoil," Journal of Fluid Mechanics, Vol. 732, sep 2013, pp. 401-444. 